\title{
Comparison between modified LST Fastfloat and conventional HF methods for pollen preparation in highly minerogenic sediments
}

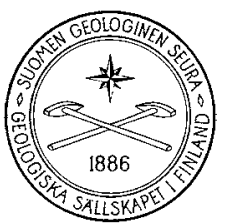

VERTAISARVIOITU KOLLEGIALT GRANSKAD PEER-REVIEWED

\author{
Tina Eskola ${ }^{\mathrm{I}^{*}}$, Riitta Kontio ${ }^{\mathrm{I}}$ and Juha Pekka LunkKa ${ }^{\mathrm{I}}$ \\ ${ }^{1}$ Oulu Mining School, P.O. Box 3000, 90014 University of Oulu, Finland
}

\begin{abstract}
Pollen analysis is a commonly used method to interpret vegetation and environmental change. The standard pollen preparation technique in minerogenic sediments involves the use of hydrofluoric acid (HF) which is highly toxic. Currently the European legislation requires that hazardous chemicals should be substituted with less hazardous or nontoxic chemicals if possible. In the present paper the authors introduce a safer pollen preparation method, based on the use of low-toxic heavy liquid lithium heteropolytungstate (LST Fastfloat) and provide instructions for pollen preparation with the LST Fastflow method. Furthermore, five paired samples were processed from clayey and silty sediments with LST Fastfloat and conventional HF methods and the pollen and spore counting results obtained from these two methods were compared to test if there is statistically significant differences between the taxa. Calculation of the $95 \%$ confidence interval revealed statistical agreement in all studied taxa except one taxon in one sample pair. However, the study revealed systematic differences within two taxa, Betula and Pinus. Thus caution is needed when comparing results obtained by HF and heavy liquid (LST Fastfloat) methods.
\end{abstract}

Keywords: Pollen preparation, heavy liquid, LST Fastfloat, hydrofluoric acid, minerogenic sediment

*Corresponding author (e-mail: tiina.eskola@oulu.fi)

Editorial handling: Niina Kuosmanen (e-mail: kuosmanen.niina@gmail.com) 


\section{Introduction}

Pollen analysis is the principal method for reconstructing the past vegetation and environmental change. Therefore, it is also one of the most important methods used to study climate change and human impact on environment (e.g. Faegri \& Iversen, 1989; Bennet \& Willis, 2001). The pollen analysis technique has been used over a century (Faegri \& Iversen, 1989) and several methods for extracting pollen from different types of sediments has been developed ever since. In many cases, the removal of inorganic and mineral particles, as well as unwanted organic impurities, is in the main role to increase pollen concentration in the prepared samples and to ensure clear and accurate identification of pollen and spores. Therefore, the selection of the most suitable method for the pollen analysis for different type of samples and the time spent in a laboratory for pollen preparation save time and effort in identification and pollen counting.

When extracting pollen from various sediment types, e.g. peat, gyttja, clay, sand-rich sediments, till or sedimentary rocks, no single method or protocol can be recommended as a standard method that ought to be used (Moore et al., 1991; Loader $\&$ Hemming, 2004) and different samples react uniquely with the same treatment (Traverse, 2007). This means that the organic content, lithology, mineralogy and the level of induration effect the selection for the different chemical and/or physical treatments when extracting and concentrating pollen (Riding \& Kyffin-Hughes, 2004). The combination of methods chosen aims to produce clean samples with no, or minimum amount of, unwanted matrix in order to save counting time, and also to decrease the identification inaccuracy. Care should be taken not to alter or loose neither the potentially valuable pollen and spore component nor the (total) concentration during the pollen extraction procedures.

It is particularly challenging to extract biostratigraphical information from the Pleistocene inter- stadial and stadial terrestrial sediments with low organic content using pollen analysis. For example, Late Pleistocene interstadial and stadial sediments deposited in lake or fluvial environments and paleosoils in formerly glaciated areas like in Finland, are almost exclusively rich in minerogenic material with a low organic content (cf. Nenonen, 1995). The extraction of pollen from interstadial / stadial sediments (silt and clay) with low organic content, has yielded low pollen concentrations when nonheavy liquid methods have been used (cf. Hirvas, 1991; Nenonen, 1995; Lunkka et al., 2008; Pitkäranta et al., 2014). The increase of a pollen concentration yield and decrease of impurities can better be achieved using heavy liquid methods rather than non-heavy liquid pollen extraction methods normally used for organic-rich sediments, such as gyttja. These methods have been widely used for example in the former Soviet Union where most of the pollen analyses of mineral-rich samples have been done using Grichuk's heavy liquid method (Grichuk, 1940).

Several different chemical processes have been developed in order to remove both organic and mineral material. Whereas there is established practise for unwanted organic material removal (potassium hydroxide digestion and acetolysis), the ways to extract mineral particles is more variable. The most commonly used chemical to remove siliceous material has been treatment with concentrated hydrofluoric acid (HF), which is extremely corrosive and dangerous chemical and one of the most hazardous acids known (Leipe et al., 2019).

The use of HF to remove siliceous particles from sediment samples containing pollen was introduced by Assarsson \& Granlund in 1924. The earliest published document introducing a heavy liquid solution technique to extract pollen with Thoulet's solution was written by Grichuk in 1937 (Leipe et al., 2019) although Thoulet's solution had already been used to concentrate diatoms from gyttja-type sediments (Hustedt, 1930). The use of Thoulet's solution (i.e. potassium iodide (KI), and mercury 
iodide $\left(\mathrm{Hg}_{2} \mathrm{I}_{2}\right)$ for flotation, originally known as Sonstadt's solution, was first proposed by Sonstadt in 1874 (Gray, 1965). The use of bromoform in microfossil heavy liquid separation was first introduced by Knox (1942) although van der Kolk used bromoform already in 1895 for mineralogical purposes (i.e. heavy mineral separation) (Gray, 1965). Since then, the most commonly used heavy liquids in microfossil heavy liquid separation have been bromoform $\left(\mathrm{CHBr}_{3}\right)$, zinc bromide $\left(\mathrm{ZnBr}_{2}\right)$ and zinc chloride $\left(\mathrm{ZnCl}_{2}\right)$, solution of potassium iodide (KI) and cadmium iodide $\left(\mathrm{CdI}_{2}\right)$, stannic chloride $\left(\mathrm{SnCl}_{4}\right)$ and Thoulet's solution (solution of potassium iodide, $\mathrm{KI}$, and mercury iodide, $\mathrm{Hg}_{2} \mathrm{I}_{2}$ ). Some of these solutions are highly toxic either on contact or inhaling the fumes what makes their use hazardous. If their use is unavoidable, extra caution should be exercised when these solutions are used in microfossil and other heavy liquid separation work. Within the European Union, all the laboratory analyses are regulated by the safety and health guidelines provided by the European Agency for Safety and Health at Work (https://osha. europa.eu/en) as well as manufacturers' chemical safety data sheets. The European legislation states that hazardous chemicals must be substituted by less hazardous or non-toxic chemicals. Therefore, it is vital to seek new or modified solutions and methods for safer microfossil work where heavy liquids are used.

The purpose of this paper is to review the toxicity of common chemicals use in heavy liquid separation and to introduce a safe heavy liquid method for the pollen sample preparation. We compare the pollen results prepared using silt and clay -rich sediments with 1) conventional HF treatment and 2) with low-toxic heavy liquid LST Fastfloat treatment on low organic silt-rich sediment. Comparing the results with two different treatments will shed light on the question whether the pollen results processed with these methods are comparable.

\section{Toxicity of commonly used heavy liquids}

Table 1 lists chemicals used in mineral material removal in pollen preparation according to their toxicity and health risks and in some cases their effect on life. Chemicals can be grouped here into three different categories where 1) highly toxic chemicals include hydrofluoric acid (HF), bromoform $\left(\mathrm{CHBr}_{3}\right)$, solution of cadmium iodide $\left(\mathrm{CdI}_{2}\right)$ and potassium iodide $(\mathrm{KI})$ and Thoulet's solution (potassium iodide (KI) and mercury iodide $\left.\left(\mathrm{Hg}_{2} \mathrm{I}_{2}\right), 2\right)$ toxic chemicals include zinc bromide $\left(\mathrm{ZnBr}_{2}\right)$, zinc chloride $\left(\mathrm{ZnCl}_{2}\right)$ and stannic chloride $\left(\mathrm{SnCl}_{4}\right)$ and 3) low toxic chemicals that include lithium and sodium heterpolytungstates (LST) and sodium polytungstate (SPT; also known as sodium metatungstate).

Most of the heavy liquids contain halogenides and therefore, they are very or moderately toxic. This has led to the use of low-toxic heavy liquids in pollen extraction. The use of heavy liquids such as sodium metatungstate (known as sodium polytungstate, SPT) and lithium -based or sodiumbased heteropolytungstates (LST), have become more common during the last decades (Van Ness et al., 2017). Here we concentrate on testing the mixture of lithium and sodium-based heteropolytungstates (LST Fastfloat) use in pollen work. LST Fastfloat is an aquaeous solution composed of the lithium and sodium salts of lowtoxic heteropolyanions.

\section{Heteropolytungstate (LST) Fastflow method - testing and comparison}

Although the use of low-toxic, tungsten-based heavy liquids such as sodium polytungstate (SPT), lithium metatungstate (LMT) and lithium or sodium heteropolytungstate (LST) have been used in palynological studies since the late 1980s 
Table 1. Toxicity of chemicals used in mineral material removal in pollen preparation.

\begin{tabular}{|c|c|c|}
\hline Relative toxicity & Chemical reagent & Chemical effects and symptoms \\
\hline \multirow{5}{*}{ Highly toxic } & Hydrofluoric acid, HF & $\begin{array}{l}\text { HF is one of the most hazardous acids known (Leipe et al., 2019). Exposure to HF can } \\
\text { cause death (ICSC, 2017a). HF absorbs through the skin and can cause serious and } \\
\text { severe burns to skin and eyes as HF is very corrosive. Inhalation of hydrofluoric acid } \\
\text { causes cough, burning sensation, shortness of breath, nausea and vomiting. Ingestion } \\
\text { causes burns in mouth and throat, abdominal pain, vomiting, collapse and shock. Skin } \\
\text { burns caused by anhydrous hydrofluoric acid (100\% concentration) as small as } 2.5 \% \text { of } \\
\text { body surface area is known to cause death (Tepperman, 1980). }\end{array}$ \\
\hline & Bromoform, $\mathrm{CHBr}_{3}$ & $\begin{array}{l}\text { Bromoform is classified as toxic (by inhalation), harmful (if swallowed), irritant (serious } \\
\text { eye irritation and skin irritation) and dangerous for the environment (toxic to aquatic } \\
\text { life with long lasting effects). Absorption of bromoform may cause agitation, dizziness, } \\
\text { unconsciousness, narcosis, tremors, pain in gastrointestinal tract and death. It may also } \\
\text { cause central nervous system disorder, cardiovascular disorders, damage to kidneys } \\
\text { and liver (Merck Material safety data sheet (MSDS); Pohanish, 2017). EPA (United States } \\
\text { Environmental Protection Agency) has classified bromoform as a probable human } \\
\text { carsinogen. }\end{array}$ \\
\hline & Zinc bromide, $\mathrm{ZnBr}_{2}$ & $\begin{array}{l}\text { Zinc bromide is classified as corrosive to skin and very toxic to aquatic life with long } \\
\text { lasting effects. Zinc bromide causes severe skin burns and eye damage. If zinc bromide } \\
\text { is ingested it may cause severe burns of the mouth and throat, severe stomach pain } \\
\text { and vomiting, dihorrea, shock, collapse and death. } 1 \mathrm{oz} \text { (ca. } 30 \mathrm{~g}, 28,35 \mathrm{~g} \text { ) of bromide } \\
\text { salts ingested is known to cause death (Gosselin et al., 1984). Bromide ion causes also } \\
\text { drowsiness, ataxia, vertigo, mania, hallucinations and coma (Gosselin et al., 1984). If } \\
\text { zinc bromide is inhaled, it may cause mucosal irritations, cough, wheezing, shortness of } \\
\text { breath and possible damage the respiratory tract. Repeated or long-term exposure may } \\
\text { cause headache, personality changes, poor appetite, lethargy and confusion (Merck } \\
\text { MSDS; Pohanish, 2017). }\end{array}$ \\
\hline & $\begin{array}{l}\text { Potassium iodide + } \\
\text { cadmium iodide } \\
\text { solution, } \mathrm{KI}+\mathrm{Cdl}_{2}\end{array}$ & $\begin{array}{l}\text { Potassium iodide causes damage to organs (thyroid) through prolonged or repeated } \\
\text { exposure if ingested. No skin or eye irritation is registered (Merck MSDS). Cadmium } \\
\text { iodide is classified as toxic if inhaled or ingested and is suspected of causing cancer. } \\
\text { Cadmium iodide may lead to damaged organs if exposure is prolonged or repeated. } \\
\text { Cadmium iodide is also very toxic to aquatic life with long lasting effects. (Sigma-Aldrich } \\
\text { MSDS) Based on the IARC evaluation, there is sufficient evidence for cadmium and } \\
\text { cadmium compounds to be classified as carcinogenic to humans (Group 1) (IARC, } \\
2012 \text { ). An oral dose of } 25 \mathrm{mg} / \mathrm{kg} \text { body weight of cadmium iodide is known to cause } \\
\text { death, caused by the damage of liver, kidneys and overall depression of respiratory and } \\
\text { circulatory centers (Wisniewska-Knypl et al., 1971). }\end{array}$ \\
\hline & $\begin{array}{l}\text { Thoulet's solution } \\
\text { (potassium iodide + } \\
\text { mercuric iodide), } \mathrm{KI}+ \\
\mathrm{Hg}_{2} \mathrm{I}_{2}\end{array}$ & $\begin{array}{l}\text { Mercury(II) iodide is classified as acutely toxic and fatal if ingested, inhaled or in contact } \\
\text { with skin and very toxic to aquatic life with long lasting effects (Merck MSDS). Mercury } \\
\text { iodide may cause damage to organs, especially kidneys, if exposure is prolonged or } \\
\text { repeated (Merck MSDS). Inorganic mercury(II) salts are nephrotoxic (Magos \& Webb, } \\
\text { 1980), and accumulates both liver and kidney (Langford \& Ferner, 1999). Mercury(II) } \\
\text { iodide causes severe damages to eyes, mucosal membranes of gastrointestinal and } \\
\text { respiratory tract, blood pressure drop, cardiac dysrhythmia, circulatory collapse and } \\
\text { kidney failure (Merck MSDS). Ingested inorganic mercury salts act corrosively, causing } \\
\text { initial effects such as painful necrotic lesions in mouth, esophagus and stomach } \\
\text { (Gerstner \& Huff, 1977), vomiting, bloody diarrhoea, hypovolaemic shock, mercurial } \\
\text { stomatitis, loss of the teeth, renal damage and death (Langford \& Ferner, 1999; Risher, } \\
\text { 2003). }\end{array}$ \\
\hline
\end{tabular}




\begin{tabular}{|c|c|c|}
\hline \multirow[t]{2}{*}{ Toxic } & Zinc chloride, $\mathrm{ZnCl}_{2}$ & $\begin{array}{l}\text { Zinc chloride is classified as a corrosive to skin and eyes causing severe damages and } \\
\text { acutely toxic and harmful if ingested (Sigma-Aldrich MSDS). Inhaling zinc chloride } \\
\text { corrodes respiratory tract and may cause cough, breathing difficulty, tachypnea, cyanosis } \\
\text { (bluish skin), nausea and vomiting, bronchopneumonia and chest pain (Pohanish, } \\
\text { 2017). Zinc chloride is corrosive on ingestion and causes sore throat and burning } \\
\text { sensation, abdominal pain, nausea and vomiting and shock or collapse (ICSC, 2017b). } \\
\text { Higher exposures either inhaled or ingested is known to cause death (e.g. Kondo et al., } \\
\text { 2016; Hjorts } \varnothing \text { et al., 1988). Zinc chloride is also very toxic to aquatic life and causes long } \\
\text { lasting effects after contamination (Sigma-Aldrich MSDS, ICSC 2017b). }\end{array}$ \\
\hline & Stannic chloride, $\mathrm{SnCl}_{4}$ & $\begin{array}{l}\text { Stannic chloride (tin tetrachloride) is corrosive liquid (Larrañaga et al., 2016) and it is } \\
\text { classified as corrosive to skin and harmful to aquatic life with long lasting effects. Stannic } \\
\text { chloride causes severe and painful skin burns and permanent eye damage. (Merck } \\
\text { MSDS; ICSC, 2004) If stannic chloride is inhalated, it may cause cough, sore throat, } \\
\text { burning sensation and difficulty in breathing. Ingestion of stannic chloride may cause } \\
\text { abdominal pain, burning sensation, shock or collapse (ICSC, 2004). Higher exposures } \\
\text { may cause death (Pohanish, 2017). }\end{array}$ \\
\hline \multirow[t]{2}{*}{ Low-Toxic } & $\begin{array}{l}\text { Lithium } \\
\text { heteropolytungstate, } \\
\text { LST }\end{array}$ & $\begin{array}{l}\text { Although stated as low-toxic, LST is classified as harmful if swallowed, harmful to aquatic } \\
\text { organisms and it may cause long-term adverse effects in the aquatic environment. Risk } \\
\text { of serious damage to eyes. Based on the tests, LST is non-irritant to skin and there is no } \\
\text { indication of mutagenic nor clastogenic effects. LST does not form volatile vapours. } \\
\text { (LST Fastfloat and LST Heavy Liquid MSDSs) }\end{array}$ \\
\hline & $\begin{array}{l}\text { Sodium polytungstate, } \\
\text { SPT }\end{array}$ & $\begin{array}{l}\text { Harmful if swallowed, harmful to aquatic life with long lasting effects. Causes serious eye } \\
\text { damage.SPT is non-irritant to skin. SPT does not form volatile vapours. (SPT GeoLiquids } \\
\text { MSDS) }\end{array}$ \\
\hline
\end{tabular}

Table 2. Previously published comparable studies between HF and heavy liquid methods in pollen analysis.

\begin{tabular}{lcccc}
\hline Reference & Microfossil group & Methods & Specific gravity $\left(\mathrm{g} / \mathrm{cm}^{3}\right)$ & Paired samples \\
\hline Björck etal., 1978 & Pollen & HFvs. ZnCl & 2.0 & 16 \\
Nakagawa et al., 1998 & Pollen & HFvs. Cdl ${ }_{2}$ and KI & 1.88 & 11 \\
Lentfer \&Boyd, 2000 & Phytoliths, pollen & HFvs. Cdl ${ }_{2}$ and KI & 2.35 & 6 \\
Zabenskie, 2006 & Pollen & HFvs. SPT & 1.95 & 2 \\
Campbell et al., 2016 & Pollen, non-pollen & HFvs. SPT & $1.88-1.91$ & 30 \\
& palynomorphs, & & & \\
Leipe etal., 2019 & microcharcoal & HF, LST, SPT & 2.1 & 5 \\
\hline
\end{tabular}

(Krukowski, 1988; Savage, 1988), relatively few comparative pollen methodology studies have been published. As far as the authors know, only six comparable studies between HF and different heavy liquid separation method have been published (Table 2).

Based on careful literature review and comparison with previously published methods (e.g.
Zabenskie et al., 2006; Zabenskie \& Gajewski, 2009; Caffrey \& Horn 2009, 2013), we introduce here a modified LST Fastflow method to extract pollen from interstadial and interglacial silt-rich sediment and compare the pollen results of the modified LST Fastflow method with the results obtained using the conventional HF method. 


\section{Materials and Methods}

The sediment samples used in this test are from Muhos, northern Ostrobothnia, Finland, from where a 54-metre-long sediment core was drilled in 2006 (lat. $64^{\circ} 811^{\prime} \mathrm{N}$, long. $26^{\circ} 032^{\prime} \mathrm{E}$, c. $29 \mathrm{~m}$ a.s.l.). The sediments in the core contain a thick sequence of Pleistocene and Holocene sediments including several diamicton units interbedded with sorted sediments (see Fig 2. Lunkka et al., 2013). The basal diamicton suite, resting upon the Neoprotezoic Muhos siltstone (so called Muhos Formation), passes into a thick sand-rich unit that contains laminated clay and silt layers. Samples from clay and silt rich sediment interval, Unit A, 29.55-29.83 m b.g.s. $(29 \mathrm{~cm}$ thick laminated clay and silt, samples
MU 1 - MU 3) (Fig. 1a ) and silt-rich Unit B, $38.74-38.81 \mathrm{~m}$ below the ground surface (b.g.s) (8 $\mathrm{cm}$ long sediment interval, samples MU 4 and MU 5) (Fig. 1b) between two diamicton units were studied.

Determining the loss on ignition (LOI) is the basic method for characterising the amount of organic matter in a sample. Loss of ignition (LOI) analysis was carried out by drying the samples in $105^{\circ} \mathrm{C}$ and heating the samples in $550{ }^{\circ} \mathrm{C}$ for 2 hours (SFS-EN 15935: 2012) (Table 3). The grain size distributions were determined using CILAS 1190 particle analysator. The samples were weighted in the ratio of 1 part soil to 10 parts $1 \%$ sodium pyrophosphate solution and placed in a rocker mixer for overnight.


Figure 1. Sediments of the studied Muhos core. Sampling depths are indicated as stars. a) Sediment unit A, 29.55 - 29.83 m b.g.s. b) Sediment unit B, 38.74 - 38.81 m b.g.s. Photos by J. Annanolli. 
Table 3. Sampled pair numbers and sampling depths, the amount of sediment used for pollen analysis, grain size distribution and loss of ignition results of tested samples.

\begin{tabular}{ccccc}
\hline Sample ID (m b.g.s.) & weight(air-dry) & water content (\%) & $\begin{array}{c}\text { Grain size } \\
\text { (Fraunhofer) }\end{array}$ & LOI (\%) \\
\hline MU 1(29.65) & $2.10 \mathrm{~g}$ & $0.91 \%$ & Clayeysilt & $1.38 \%$ \\
MU 2(29.70) & $2.71 \mathrm{~g}$ & $0.84 \%$ & silt & $1.29 \%$ \\
MU 3(29.81) & $2.30 \mathrm{~g}$ & $1.03 \%$ & silt & $1.63 \%$ \\
MU 4(38.75) & $2.07 \mathrm{~g}(\mathrm{LST})-2.14 \mathrm{~g}(\mathrm{HF})$ & n.a. & silt & n.a. \\
MU 5(38.78) & $1.95 \mathrm{~g}$ & $1.32 \%$ & silt & $4.24 \%$ \\
\hline
\end{tabular}

\subsection{Pollen extraction and analysis}

Samples taken for pollen analysis were homogenized and divided into two subsamples. The divided subsamples were treated with both by a heavy liquid separation (LST Fastfloat, a mixture of lithium and sodium heteropolytungstate) and by the conventional HF-method. Sodium pyrophosphate was used as a deflocculant before the HF treatment to increase the efficiency of clay particles removal (Bates et al., 1978).

\subsubsection{Modified LST Fastfloat procedure}

The LST procedure used for the selected samples in Table 3 included the following steps:

1. Air-dry -weighted sample is placed in a $50 \mathrm{ml}$ conical-bottom polypropylene centrifuge tube and two Lycopodium spore tablets per sample are added $(\mathrm{x}=18583$ grains/tablet, batch number 483216$)$ into the tube.

2. Addition of $5 \mathrm{ml} 10 \% \mathrm{HCl}$, let the pellets dissolve and stir the sample with a vortex mixer. Centrifuge at $4000 \mathrm{rpm}$ for $5 \mathrm{~min}$ and decant the supernatant.

3. Addition of ca. $30 \mathrm{ml} \mathrm{(2/3} \mathrm{of} \mathrm{the} \mathrm{centrifuge}$ tubes' volume) distilled water and stir with a vortex mixer. Rinse the brim with a small amount of ethanol (ethyl alcohol) to break the surface tension. Centrifuge at $4000 \mathrm{rpm}$ for 5 min, decant the supernatant.

4. Addition of ca. $30 \mathrm{ml} 10 \% \mathrm{KOH}$, vortex the sample and leave in the water bath $\left(95^{\circ} \mathrm{C}\right)$ for $8 \mathrm{~min}$. Centrifuge at $4000 \mathrm{rpm}$ for $5 \mathrm{~min}$, decant the supernatant. Wash the sample with c. $30 \mathrm{ml}$ of distilled water, vortex, rinse the brim with a small amount of ethanol and centrifuge at $4000 \mathrm{rpm}$ for $5 \mathrm{~min}$. Repeat washing with distilled water.

5. Addition of $5 \mathrm{ml} 10 \% \mathrm{HCl}$, vortex and centrifuge at $4000 \mathrm{rpm}$ for $5 \mathrm{~min}$, decant. Acidic solution prior the heavy liquid step may help removing the non-pollen material (Nakagawa et al., 1998; Zabenskie \& Gajewski, 2009).

6. Addition of ca. $20 \mathrm{ml}$ distilled water, vortex, rinse the brim with a small amount of ethanol and centrifuge at $4000 \mathrm{rpm}$ for $5 \mathrm{~min}$. (Make sure all the distilled water is poured off to avoid the dilution of the LST Fastfloat).

7. Addition of $5 \mathrm{ml} \mathrm{LST} \mathrm{Fastfloat} \mathrm{at} 1.95 \mathrm{~g} / \mathrm{cm}^{3}$, place the centrifuge tube in stand with a holder and vortex for $5 \mathrm{~min}$. Centrifuge at $1800 \mathrm{rpm}$ for $10 \mathrm{~min}$, decant the supernatant (with pollen and spores) into new $50 \mathrm{ml}$ centrifuge tube.

8. Fill the centrifuge tube with distilled water and add a drop of ethanol, centrifuge at $4000 \mathrm{rpm}$ for $5 \mathrm{~min}$, decant the water-LST -mixture to a separate container for later recycling.

9. Add ca. $20 \mathrm{ml}$ glacial acetic acid $\left(\mathrm{CH}_{3} \mathrm{COOH}\right)$, vortex (vigorously), centrifuge at $4000 \mathrm{rpm}$ for $5 \mathrm{~min}$ and decant the supernatant.

10. Add ca. $20 \mathrm{ml}$ of acetolysis mixture (9 parts acetic anhydride $\left(\left(\mathrm{CH}_{3} \mathrm{CO}\right)_{2} \mathrm{O}\right)$ and 1 part concentrated sulphuric acid $\left(\mathrm{H}_{2} \mathrm{SO}_{4}\right)$ ), stir carefully and place the sample in the water bath 
$\left(95^{\circ} \mathrm{C}\right)$ for $3 \mathrm{~min}$. Centrifuge at $4000 \mathrm{rpm}$ for 5 min, decant the supernatant.

11. Add ca. $20 \mathrm{ml}$ glacial acetic acid $\left(\mathrm{CH}_{3} \mathrm{COOH}\right)$, vortex, centrifuge at $4000 \mathrm{rpm}$ for $5 \mathrm{~min}$ and decant the supernatant.

12. Wash the sample with ca. $20 \mathrm{ml}$ distilled water, vortex, rinse the brim with a small amount of ethanol and centrifuge at $4000 \mathrm{rpm}$ for $5 \mathrm{~min}$, decant the supernatant.

13. Add ca. $20 \mathrm{ml}$ ethanol, vortex, centrifuge at $4000 \mathrm{rpm}$ for $5 \mathrm{~min}$, decant the supernatant. Stain the sample with a drop of safranin, vortex. Add ca. $20 \mathrm{ml}$ ethanol, vortex, centrifuge at $4000 \mathrm{rpm}$ for $5 \mathrm{~min}$, decant the supernatant.

14. Add ca. $20 \mathrm{ml}$ of tertiary butyl alcohol (TBA), vortex, centrifuge at $4000 \mathrm{rpm}$ for $5 \mathrm{~min}$ and decant the supernatant.

15. Add few drips of silicone oil as a mounting medium and stir with a glass rod. Allow the TBA to evaporate (in fume cupboard) at least for 24 hours, add few drops of silicone oil if necessary.

\subsubsection{Conventional HF procedure}

Steps 1-6 were identical in both, the modified LST Fastfloat-procedure (see above) and the HFprocedure. Decanted supernatants were examined under a light microscope to ensure that there was no loss of pollen or spores.

7. Add ca. $20 \mathrm{ml}$ of $10 \%$ sodium pyrophosphate $\left(\mathrm{Na}_{4} \mathrm{P}_{2} \mathrm{O}_{7}\right)$, stir vigorously in vortex mixer and transfer the sample in a water bath $\left(95^{\circ} \mathrm{C}\right)$ for 10-20 min. Centrifuge at $3000 \mathrm{rpm}$ for $5 \mathrm{~min}$, decant the supernatant. Step 7 can be repeated several times if the sample contains lots of clay particles.

8. Add ca. $30 \mathrm{ml}$ of distilled water, vortex, centrifuge at $4000 \mathrm{rpm}$ for $5 \mathrm{~min}$, decant the supernatant. Repeat x 5.

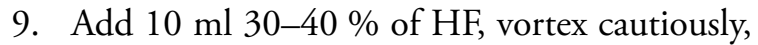
place the sample to a water bath $\left(95^{\circ} \mathrm{C}\right)$ for $10 \mathrm{~min}$. Centrifuge at $4000 \mathrm{rpm}$ for $5 \mathrm{~min}$, decant.
10. Add ca. $30 \mathrm{ml}$ warm $10 \% \mathrm{HCl}$, vortex cautiously, centrifuge at $4000 \mathrm{rpm}$ for $5 \mathrm{~min}$, decant the supernatant.

11. Add ca. $30 \mathrm{ml}$ of distilled water, vortex, ad a drop of ethanol, centrifuge at $4000 \mathrm{rpm}$ for 5 min, decant the supernatant.

Steps 9-15 listed in LST Fastfloat-procedure are prepared in parallel with the HF method.

A minimum of 700 terrestrial vascular pollen and spores were counted from each sample to yield statistical reliability. The samples were examined using Nikon eclipse 50i light microscope with $400 \mathrm{x}$ magnification and at least half of the slide was counted to minimize the possible uneven distribution of pollen and spores. Pollen and spore percentages were counted from the total sum which include arboreal and non-arboreal pollen, aquatic pollen, spores and unidentified pollen grains. Pollen percentage diagram was drawn with the TILIA program version 2.0.41.

\section{2. $95 \%$ Confidence intervals}

Counting pollen or any microfossil gives only an estimation of the true value of the microfossil population (e.g. Mosimann, 1965; Maher, 1972; Bennett \& Willis, 2001). Even if the same sample is counted repeatedly, the results will not be exactly the same every time. Calculating $95 \%$ confidence intervals gives the minimum and maximum limits for the true proportion of specified taxon with a probability of 0.95 (Maher, 1972). In this study the $95 \%$ confidence intervals were calculated for the taxa reaching 5 or more percent at least in one sample pair. $95 \%$ Confidence intervals, expressed as margins of error, were calculated for pollen proportions within the pollen sum as presented by Mosimann (1965). 


\section{Results}

The visual and microscopic inspection of the chemically processed pollen samples differs markedly. The organic residual sample volume in the LST Fastfloat samples is significantly smaller than in the samples treated with conventional HF + sodium pyrophosphate procedure. In addition to the pollen, the residual in the LST Fastfloat samples contain only small amount of smallsized minerogenic particles whereas the samples processed with HF included mainly minerogenic particles and coarse organic fragments. Altogether
45 and 47 taxa were identified from LST Fastfloat and HF samples, respectively.

The pollen results of the comparative counts in total are presented in Fig. 2. Overall, Betula dominates the tree pollen spectra at both sampling levels after both HF and LST treatments. Other tree pollen include Pinus and Alnus and few percentages of Picea at the lower sampling level. Cyperaceae and Poaceae pollen percentages are around $5 \%$ while Salix and Ericaceae constitute both only 1-2 \% of the total pollen and spores counted. Spaghnum and Polypodiaceae spores range from 5 to $15 \%$ of the total pollen and spores sum.
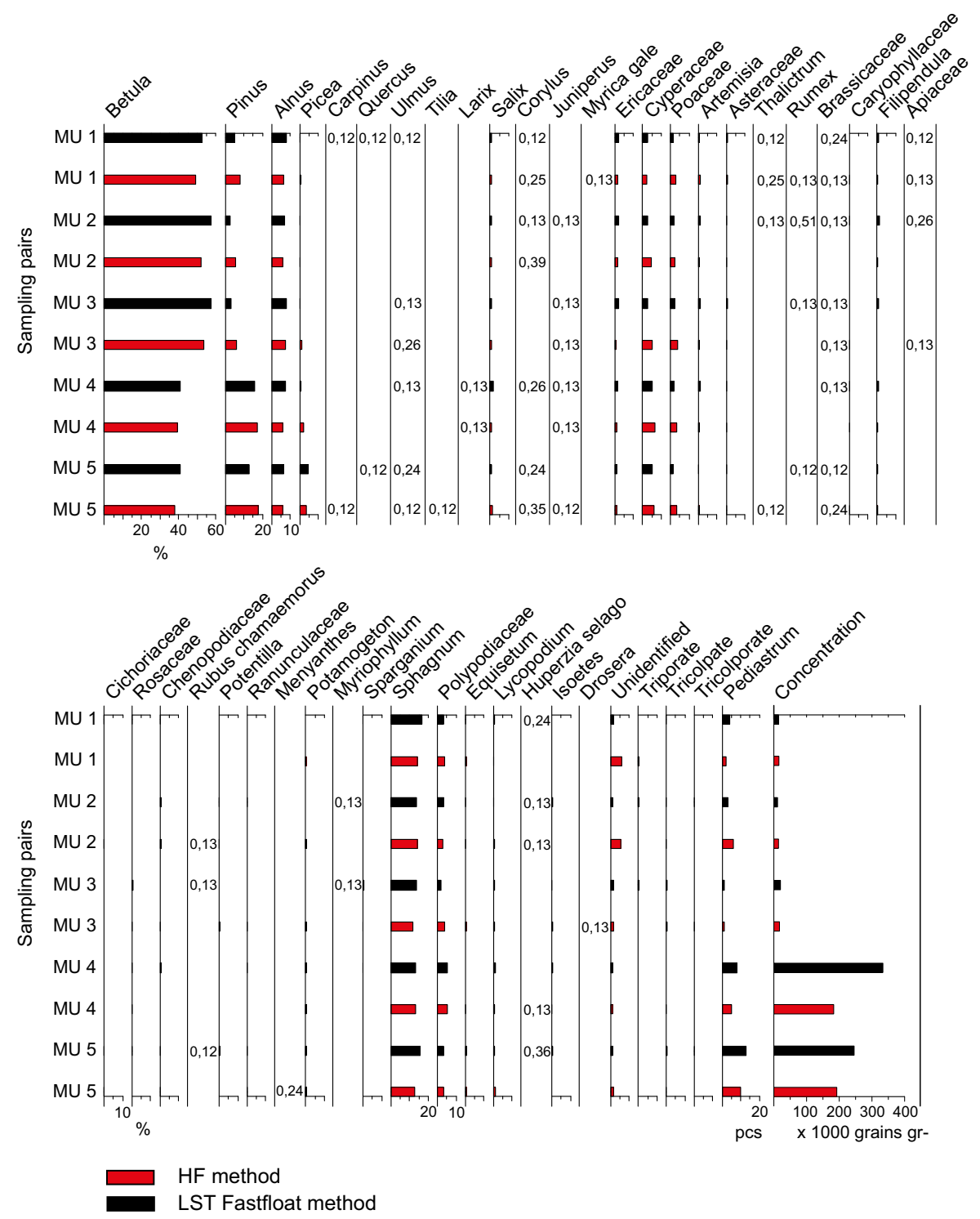

Figure 2. Results of pollen count in paired samples expressed as percentages and total concentration expressed as grains per gram, both for LST Fastfloat and HF samples. Betula includes B. tree + B. nana. Worn and thin-walled pollen are included. 

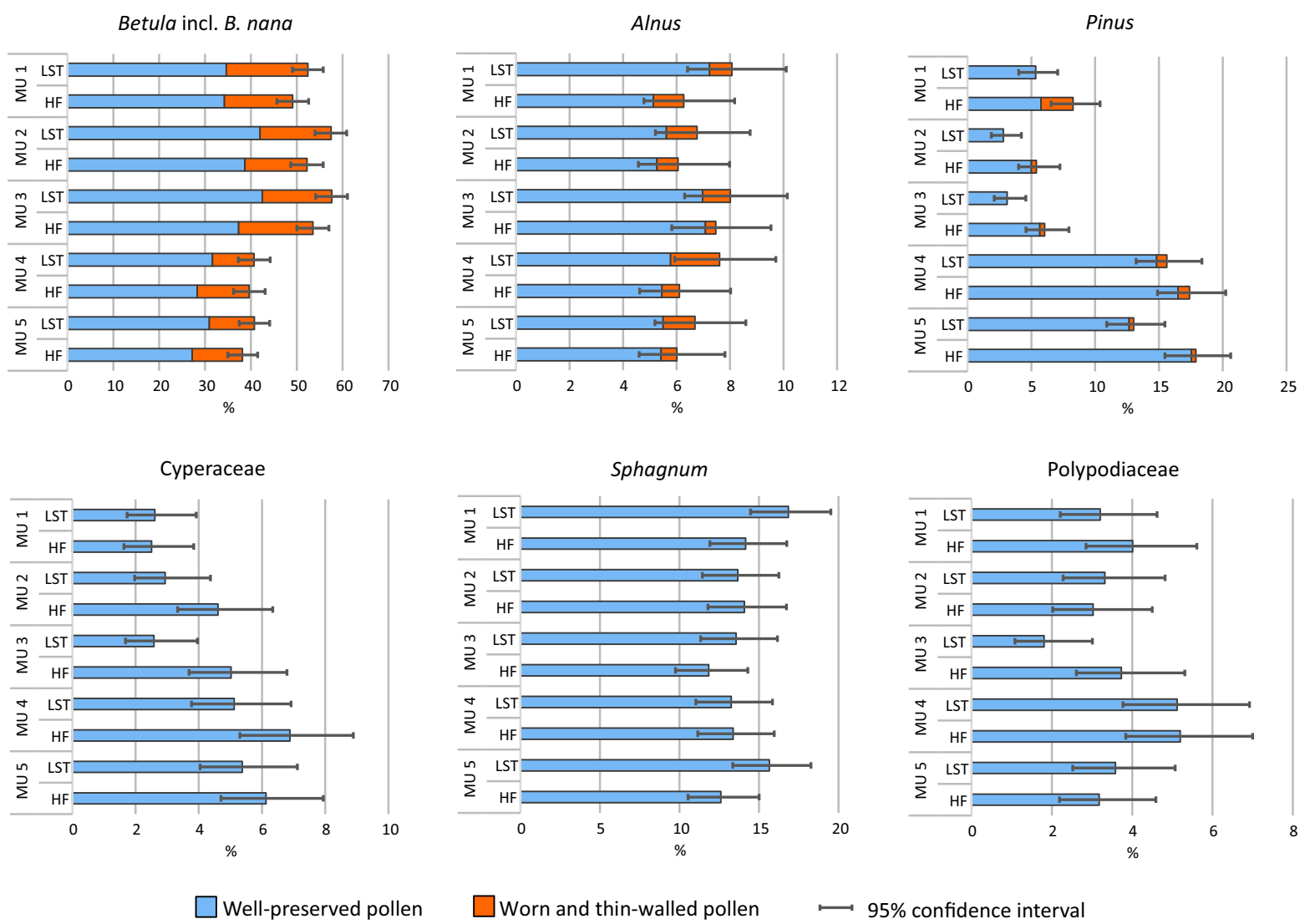

Figure 3. Selected taxa for the statistical comparison between HF and LST Fastfloat samples. Minimum of $5 \%$ of the total sum at least in one sample pair with $95 \%$ confidence interval.

A total amount of 6 different taxa (Betula, Pinus, Alnus, Cyperaceae, Polypodiaceae, Sphagnum) that reached at least $5 \%$ in at least one pair of the samples treated with the HF and LST were selected for a more detailed study to test differences of the results of the HF and LST procedures. Wellpreserved Betula, Pinus and Alnus and poorly preserved (broken and thin-walled pollen) Betula, Pinus and Alnus were counted separately and combined in the taxa diagrams shown in Fig. 3. Visual examination of the taxa shows only minor differences in pollen proportions concerning both major and minor taxa with the maximum difference of $5.18(5.2 \%) \%$ for the most common taxa, i.e. Betula tree including B. nana.

Statistically the samples processed with either HF or LST are comparable except in one sampling pair (MU 3) for Pinus although the statistics remain only slightly under the statistical significance level of $95 \%$. In sampling pair MU 5 the $95 \%$ confidence limit overlap is zero. However, if only well-preserved Pinus-pollen are considered then the significance level for comparison of Pinus is under a threshold significance level $95 \%$ only in sample pair MU 5 .

The taxa reaching $5 \%$ or over in the sample pair MU 1 at 29.65 metre-level comprise Betula, Pinus, Alnus and Sphagnum. All the mentioned taxa are statistically comparable. The relative abundances of Betula, Alnus and Sphagnum are higher in LST Fastfloat samples whereas Pinus percentage is higher in HF sample. The well-reserved Pinus proportion is almost the same (HF 5.76\% and LST Fastfloat $5.34 \%$ ) but the difference comes from the crumbled Pinus pollen: the HF sample contains 
$2.51 \%$ worn and thin-walled Pinus pollen whereas no such Pinus pollen is registered in LST Fastfloat sample. Overall, the proportion of relatively small pollen, Betula, Alnus and somewhat Sphagnum are higher in LST Fastfloat sample and relatively big size pollen Pinus is higher in HF sample. Cyperaceae and Polypodiaceae represent less than $5 \%$ of the taxa, and although not statistically significant the relative difference in the sample pair MU 1 is less than $1 \%$. The discrepancy between concentration values in LST Fastfloat and HF samples is minor; the concentration value for LST Fastfloat sample is ca. 15500 grains gr $^{-}$whereas the concentration for HF sample is ca. 14500 grains gr-

The individual taxa abundance of $5 \%$ or over in sample pair MU 2 at 29.70 metre-level comprise the same taxa as in sample pair MU 1, i.e. Betula, Pinus, Alnus and Sphagnum, and the taxa are all statistically comparable. The relative abundances of Betula and Alnus are slightly higher in LST Fastfloat sample whereas the relative abundance of Pinus is much higher in HF sample $(5.4 \%)$ compared to LST Fastfloat sample $(2.8 \%)$. Cyperaceae and Polypodiaceae represent less than $5 \%$ of the taxa, and although not statistically significant they relative difference in the sample pair MU 2 is less than $1.5 \%$. The concentration values are rather low for both LST Fastfloat and HF samples (ca. 11400 grains gr and 14200 grains gr'$^{-}$, respectively); concentration in the LST Fastfloat is ca. $20 \%$ smaller than in the HF sample.

Betula, Alnus, Pinus, Sphagnum and Cyperaceae reach the $5 \%$-level in the sample pair MU 3 at 29.81 metre-level of the core. Betula, Alnus and Sphagnum percentages are slightly higher in LST Fastfloat sample. In contrast, Pinus and Cyperaceae percentages are higher in HF sample. Results are statistically comparative considered the $95 \%$ confidence interval except for Pinus, where the maximum LST error estimation and minimum HF error estimation differ less than $0.1 \%$ which is just outside the $95 \%$ confidence interval. The abundance of Polypodiaceae is less than $5 \%$. The concentration values for LST Fastfloat is ca. 20200 grains gr- and for HF is ca. 17200 grains gr', thus ca. $15 \%$ smaller than the LST Fastfloat concentration.

Sample pair MU 4 at 38.75 metre-level contains six taxa reaching at least $5 \%$. Overall, the comparison between the HF and LST Fastfloat pollen percentages show only minor differences. Proportions of Alnus and Betula are higher in LST Fastfloat sample, latter only slightly. The proportions of Pinus and Cyperaceae are higher in the sample treated with the HF procedure. The presence of Sphagnum and Polypodiaceae are at the same level. All the taxa are statistically comparable. The concentration values differ drastically between the LST Fastfloat and HF samples: the LST Fastfloat concentration (ca. 333700 grains gr') is nearly two times higher than the concentration in HF sample (ca. 183200 grains gr').

Sample pair MU 5 at 38.78 metre-level comprises five taxa with the abundance over $5 \%$. Relative abundances of Betula, Alnus and Sphagnum are slightly higher in LST Fastfloat sample where relative abundances of Pinus and slightly Cyperaceae are higher in HF samples. The taxa are statistically comparable except for Pinus where the $95 \%$ confidence interval is just $0.01 \%$ outside the error. The abundance of Polypodiaceae is less than $5 \%$. The pollen and spore concentration in the LST Fastfloat sample is ca. 245400 grains gr whereas the concentration for the HF sample is ca. 192600 grains gr- thus nearly $22 \%$ smaller than the LST Fastfloat concentration.

\section{Discussion and conclusions}

Sediments deposited in e.g. fluvial and large lake basins as well as paleosols and beach environments deposited in formerly glaciated areas, like in Fennoscandia, commonly contain organic matter including pollen within mainly minerogenic sediments. Thus it is important to use reliable and non-toxic methods for pollen extraction and pollen sample preparation. Here the protocol of a modified LST Fastfloat method is introduced and suggested for a preferred alternative to the conventional 
HF method and other types of heavy liquid separations for pollen extraction from interstadial and interglacial sediments rich in minerogenic matter. The main benefit of using the modified LST Fastfloat method is that it is non-toxic and safe to use. In addition, the use of the modified LST Fastfloat method diminishes mineral matter in the final pollen slides compared to samples that are made with conventional HF method.

When extracting pollen with heavy liquid separation, the density of the heavy liquid plays an important role. Neither the density of the heavy liquid used cannot be too low, as there is a risk of losing heavier pollen, nor too high, as impurities may conceal critical pollen and also slow down the time spent when counting the sample. The exact density of the pollen and spores is not know as it varies because of the size and shape of the pollen grain, thickness of the pollen wall, different chemical treatments as well as the age of the pollen grain (Juvigné, 1973; Regnéll \& Everitt, 1996). Juvigné (1973) suggest as high as $1.9 \mathrm{~g} / \mathrm{cm}^{3}$ density values for pollen and spores at age of beginning of the Würm (Weichselian) whereas recent pollen and spore exine density values are of $1.4 \mathrm{~g} / \mathrm{cm}^{3}$. In the study of Regnell and Everitt (1996) the recent pollen were "chemically fossilized" and measured mean isodensities in $\mathrm{CsCl} /$ water for e.g. Betula pendula and Pinus sylvestris were $1.506 \mathrm{~g} / \mathrm{cm}^{3}$ and $1.473 \mathrm{~g} / \mathrm{cm}^{3}$, respectively.

Overall, pollen counts from identical sample pairs (MU 1-5) treated with the modified LST Fastfloat and the conventional HF method did not differ markedly, and the differences were neither systematic nor significant within one taxon except of Betula and Pinus. Percentages of Betula were systematically slightly higher in LST -processed samples but yet within the $95 \%$ confidence interval whereas percentages of Pinus were slightly higher in HF -processed samples and that one sample was outside of the $95 \%$ confidence interval. However, the difference in this one sample pair was only one hundredth of a percent. Based on our results, it is suggested that conventional $\mathrm{HF}$ and LST -processed samples are comparable. Caution is nevertheless suggested, as there are published only few comparable studies between heavy liquid method, especially LST, and HF methods.

There are no systematic difference in the concentration values. Altogether two Lycopodium spore tablets were added to every sample. At samples MU 1, MU 2 and MU 3 the concentration values are approximately at the same level. At samples MU 4 and MU 5 the concentration values are higher in the samples which are treated with the LST Fastfloat method. The concentration values at samples MU 4 and 5 may not necessarily represent the true concentration, as the counted marker grain (Lycopodium spores) related to counted pollen is too small for robust concentration. The counted marker grains per counted fossil pollen grains should ideally be between 1:5 to 1:1 (Maher, 1981; Moore et al., 1991) whereas the relationship between counted marker grains (Lycopodium spores) and counted fossil pollen were at samples MU 4 and 5 from 1:10 even to 1:20. This big difference in the fossil pollen: marker grain -ratio hampers the correlation and may thus be misleading. The big difference between the concentration values in LST Fastfloat and HF -processed samples at samples MU 4 and MU 5 cannot be explained based on the results. The physical properties of the MU 4 and MU 5 samples is rather similar when considered the grain size distribution but the organic content is approximately three times higher in the MU 5 and most likely also in MU4 samples, as the organic content could not be measured from sample MU 4 because of the small sample size. The depositional age of the sample, including its pollen is not relevant, as the Lycopodium marker grains added during the sample preparation are of the same age and density in both LST Fastfloat and HF treatments. Therefore further research needs to be done to shed light to this question.

This study clearly indicates that the pollen results obtained using modified LST Fastfloat samples can be compared with the pollen results of the samples treated with the conventional HF method. The modified LST Fastfloat -processed samples are safer to produce and the samples are 
cleaner and more efficient for counting, as also noted by Nakagawa et al. (1998) and Campbell et al. (2016).

\section{Acknowledgements}

The authors thank David Simpson at the Polytungstate Europe for providing information about LST Fastfloat. Teija Alenius and Normunds Stivrinš are thanked for their valuable comments that helped to improve the manuscript.

\section{References}

Assarsson, G. \& Granlund, E., 1924. En metod för pollenanalys av minerogena jordarter. Geologiska Föreningens I Stockholm Förhandlingar 46, 76-82.

Bates, C.D., Coxon, P. \& Gibbard, P.L., 1978. A new method for the preparation of clay-rich sediment samples for palynological investigation. New Phytologist 81, 459-463. https://doi.org/10.1111/j.1469-8137.1978.tb02651.x

Bennett, K.D. \& Willis, K.J., 2001. Pollen. In: Smol, J.P., Birks, H.J.B., Last, W.M. (eds). Tracking environmental change Using Lake Sediments. Volume 3: Terrestrial, Algal, and Siliceous Indicators. Kluwer Academic Publisher, Dordrecht, The Netherlands, pp. 5-32.

Björck, S., Persson, T. \& Kristersson, I., 1978. Comparison of two concentration methods for pollen in minerogenic sediments. Geologiska Föreningens I Stockholm Förhandlingar 100, 107-111. https://doi.org/10.1080/11035897809448568

Caffrey, M.A. \& Horn, S.P. 2009. Lithium Heteropolytungstate (LST): A Non-toxic Heavy Liquid for Extracting Pollen and Other Palynomorphs from Lake Sediments and Soils. Poster, Annual meeting of AASP - The Palynological Society, Johnson City, Tennessee.

Caffrey, M.A. \& Horn, S.P., 2013. The use of lithium heteropolytungstate in the heavy liquid separation of samples which are sparse in pollen. Palynology 37, 143150. https://doi.org/10.1080/01916122.2012.736417

Campbell, J.F.E., Fletcher, W.J., Hughes, P.D. \& Shuttleworth, E.L., 2016. A comparison of pollen extraction methods confirms dense-media separation as a reliable method of pollen preparation. Journal of Quaternary Science 31, 631-640. https://doi.org/10.1002/jqs.2886

Faegri, K. \& Iversen, K., 1989. Textbook of Pollen Analysis. 4th edition. John Wiley \& Sons, Chichester, $328 \mathrm{p}$.

Gerstner H.B. \& Huff, J.E., 1977. Clinical toxicology of mercury. Journal of Toxicology and Environmental Health 2, 491-526. https://doi.org/10.1080/15287397709529452

Gosselin, R.E., Smith, R.P. \& Hodge, H.C., 1984. Clinical Toxicology of Commercial Products. 5th edition. Williams and Wilkins, Baltimore, London, $112 \mathrm{p}$.

Gray, J., 1965. Extraction Techniques. In: Kummel, B., Raup, D. (eds.), Handbook of Paleontological Techniques. Freeman, San Francisco, pp. 530-587.
Grichuk, V.P., 1940. Method of treatment of the sediments poor in organic remains for the pollen analysis. Problemi fizicheskoi geographii 8, 53-58. (in Russian)

Hirvas, H., 1991. Pleistocene stratigraphy of Finnish Lapland. Geological Survey of Finland, Bulletin 454, $123 \mathrm{p}$.

Hjortsø, E., Qvist, J., Bud, M.I., Thomsen, J.L., Andersen, J.B., Wiberg-Jørgensen, F., Jensen, N.K., Jones, R., Reid, L.M. \& Zapol W.M., 1988. ARDS after accidental inhalation of zinc chloride smoke. Intensive Care Medicine 14, 1724. https://doi.org/10.1007/BF00254116

Hustedt, F. 1930. Die Kieselalgen Deutschlands, Österreichs und der Schweiz. Dr. L. Rabenhorst's KryptogamenFlora von Deutschland, Österreich und der Schweiz 7 , $920 \mathrm{p}$.

International Agency for Research on Cancer (IARC), 2012. Cadmium and cadmium compounds. In: IARC monographs on the evaluation of carcinogenic risks to humans: A review of human carcinogens. Part C: Arsenic, metals, fibres and dusts. Volume 100C. World Health Organization, Lyon, 121-141.

International Chemical Safety Card (ICSC) 2004. Tin(IV) chloride (anhydrous). The International Labor Organization.

International Chemical Safety Card (ICSC), 2017a. Hydrofluoric acid (70\% aqueous solution). The International Labor Organization.

International Chemical Safety Card (ICSC), 2017b. Zinc chloride. The International Labor Organization.

Juvigné, E., 1973. Densité des exines de quelques espèces de pollens et spores fossils. Annales de la Société géologique de Belgique 96, 363-374. (abstract in English)

Knox, A.S., 1942. The use of bromoform in the separation of noncalcareous microfossils. Science 95, 307-308. https://doi.org/10.1126/science.95.2464.307

Kondo, T., Takahashi, M., Watanabe, S., Ebina, M., Mizu, D., Ariyoshi, K., Asano, M., Nagasaki, Y. \& Ueno Y., 2016. An autopsy case of zinc chloride poisoning. Legal Medicine 21, 11-14. https://doi.org/10.1016/j.legalmed.2016.05.002

Krukowski, S.T., 1988. Sodium metatungstate: a new heavy-mineral separation medium for the extraction of conodonts from insoluble residues. Journal of Paleontology 62,314-316. https://doi.org/10.1017/S0022336000030018 
Langford, N.J. \& Ferner, R.E., 1999. Toxicity of mercury. Journal of Human Hypertension 13, 651-656.

Larrañaga, M.D., Lewis Sr., R.J. \& Lewis, R.A., 2016. Hawley’s Condenced Chemical Dictionary. 16th edition. John Wiley \& Sons, Inc., Hoboken, New Jersey, 1547 p.

Leipe, C., Kobe, F. \& Müller, S., 2019. Testing the performance of sodium polytungstate and lithium heteropolytungstate as non-toxic dense media for pollen extraction from lake and peat sediment samples. Quaternary International 516, 207-214.

https://doi.org/10.1016/j.quaint.2018.01.029

Lentfer, C.J. \& Boyd, W.E., 2000. Simultaneous Extraction for Phytoliths, Pollen and Spores from Sediment. Journal of Archaeological Science 27, 363-372.

https://doi.org/10.1006/jasc.1998.0374

Loader, N.J. \& Hemming, D.L., 2004. The stable isotope analysis of pollen as an indicator of terrestrial palaeoenvironmental change: a review of progress and recent developments. Quaternary Science Reviews 23, 893-900. https://doi.org/10.1016/j.quascirev.2003.06.015

Lunkka, J.P., Murray, A. \& Korpela, K., 2008. Weichselian sediment succession at Ruunaa, Finland, indicating a Mid-Weichselian ice-free interval in eastern Fennoscandia. Boreas 37, 234-244. https://doi.org/10.1111/j.1502-3885.2007.00021.x

Lunkka, J.P., Peuraniemi, V. \& Nikarmaa, T., 2013. Application of till geochemical and indicator mineral data to the interpretation of the thick till sequence at Muhos, northern Finland. Geochemistry: Exploration, Environment, Analysis 13, 183-193.

https://doi.org/10.1144/geochem2012-119

Magos, L. \& Webb, M., 1980. The interactions of selenium with cadmium and mercury. Critical Reviews in Toxicology 8, 1-42. https://doi.org/10.3109/10408448009037490

Maher, L.J. Jr., 1972. Nomograms for computing 0.95 confidence limit of pollen data. Review of Palaeobotany and Palynology 13, 85-93. https://doi.org/10.1016/0034-6667(72)90038-3

Maher, L.J. Jr., 1981. Statistics for microfossil concentration measurements employing samples spiked with marker grains. Review of Palaeobotany and Palynology 32, 153191. https://doi.org/10.1016/0034-6667(81)90002-6

Moore, P.D., Webb, J.A. \& Collinson, M.E., 1991. Pollen analysis. 2nd edition. Blackwell Science, Oxford, 216 p.

Mosimann, J.E., 1965. Statistical Methods for the Pollen Analyst: Multinomial and Negative Multinomial Techniques. In: Kummel, B., Raup, D. (eds.). Handbook of Paleontological Techniques. Freeman, San Fransisco, pp. 636-673.

Nakagawa, T., Brugiapaglia, E., Digerfeldt, G., Reille, M., de Beaulieu, J.-L. \& Yasuda, Y., 1998. Dense-media separation as a more efficient pollen extraction method for use with organic sediment/deposit samples: comparison with the conventional method. Boreas 27, 15-24.

https://doi.org/10.1111/j.1502-3885.1998.tb00864.x

Nenonen, K., 1995. Pleistocene Stratigraphy and Reference
Sections in Southern and Western Finland. Geological Survey of Finland, Kuopio, 205 p.

Pitkäranta, R., Lunkka, J.P. \& Eskola, K.O., 2014. Lithostratigraphy and Optically Stimulated Luminescence age determinations of pre-Late Weichselian deposits in the Suupohja area, western Finland. Boreas 43, 193-207. https://doi.org/10.1111/bor. 12030

Pohanish, R.P., 2017. Sittig's Handbook of Toxic and Hazardous Chemicals and Carcinogens. 7th edition. William Andrew, Oxford, Cambridge, 3613 p.

Regnéll, J. \& Everitt, E., 1996. Preparative centrifugation - a new method for preparing pollen concentrates suitable for radiocarbon dating by AMS. Vegetation History and Archaeobotany 5, 201-205.

Riding, J.B. \& Kyffin-Hughes, J.E., 2004. A review of the laboratory preparation of palynomorphs with a description of an effective non-acid technique. Revista Brasileira de Paleontologia 7, 13-44.

Risher, J.F., 2003. Elemental mercury and inorganic mercury compounds: human health aspects. Concise International Chemical Assessment Document 50, World Health Organization, Geneva.

http://www.who.int/ipcs/publications/cicad/en/cicad50. pdf

Savage, N.M., 1988. The use of sodium polytungstate for conodont separations. Journal of Micropalaeontology 7, 39-40. https://doi.org/10.1144/jm.7.1.39

Sonstadt, E., 1874. Note on a new method of taking specific gravities, adapted for special cases. Chemical News and Journal of Physical Science 29, 127-128.

Tepperman, P.B., 1980. Fatality Due to Acute Systemic Fluoride Poisoning Following a Hydrofluoric Acid Skin Burn. Journal of Occupational Medicine 22, 691-692.

Traverse, A., 2007. Paleopalynology. 2nd edition. Springer, Berlin, $816 \mathrm{p}$.

Van Ness, B.G., Black, M.K., Gullett, C.R. \& O’Keefe, J.M.K., 2017. A recycling method for $\mathrm{LST}^{\oplus}$ contaminated during heavy liquid separation in palynological processing. Palynology 41, 498-503.

https://doi.org/10.1080/01916122.2017.1283368

Wisniewska-Knypl, J.M., Jablonska, J. \& Myslak, Z., 1971. Binding of Cadmium on Metallothionein in Man: An Analysis of a Fatal Poisoning by Cadmium Iodide. Archives of Toxicology 28, 46-55.

Zabenskie, S., 2006. Post-Glacial Climatic Change on Boothia Peninsula, Nunavut, Canada. M.Sc. Thesis, University of Ottawa, Canada, 98 p.

Zabenskie, S., Peros, M. \& Gajewski, K., 2006. The use of heavy-liquids in the separation of pollen from Arctic lake sediments. Canadian Association of Palynologists, Newsletter 29, 5-7.

Zabenskie, S. \& Gajewski, K., 2009. Processing Arctic sediments including heavy-liquid (Sodium Polytungstate (SPT)) concentration of pollen grains. University of Ottawa.

[http://www.lpc.uottawa.ca/resources/pollen $\% 20-\% 20$ heavy\%20liquid.html] 